\title{
More melanized males bite stronger but run slower: potential performance trade-offs related to melanin-based coloration
}

\author{
LUIS M. SAN-JOSE ${ }^{1 *}$, KATLEEN HUYGHE $^{2}$, JOHAN SCHUERCH ${ }^{1}$ and \\ PATRICK S. FITZE ${ }^{1,3,4,5}$
}

\author{
${ }^{1}$ Department of Ecology and Evolution, University of Lausanne, Le Biophore, 1015 Lausanne, \\ Switzerland \\ ${ }^{2}$ Department of Biology, University of Antwerp, Universiteitsplein 1, 2610 Antwerp, Belgium \\ ${ }^{3}$ Department of Biodiversity and Evolutionary Biology, Museo Nacional de Ciencias Naturales (MNCN, \\ CSIC), José Gutiérrez Abascal 2, 28006 Madrid, Spain \\ ${ }^{4}$ Instituto Pirenaico de Ecología (MNCN, CSIC), Ntra. Señora de la Victoria, 22700 Jaca, Spain \\ ${ }^{5}$ Fundación Araid, Edificio CEEI Aragón, María de Luna 11, 50018 Zaragoza, Spain
}

Received 16 November 2016; revised 28 March 2017; accepted for publication 28 March 2017

\begin{abstract}
Although the signalling role of melanin-based coloration has been largely debated, an increasing number of studies support its relationship to different fitness-related traits. However, whether melanin-based coloration could also function as an indicator of performance has been barely explored despite the influence that performance has on fitness. We investigated the relationship between melanin-based coloration and bite force and sprint speed in male common lizards, Zootoca vivipara. Melanin-based coloration predicted performance, being positively and negatively related to bite force and sprint speed. The association between melanin-based coloration and bite force is mediated by positive associations between coloration and head and body size. We did not find an association between coloration and any morphological traits determining sprint speed and the driver of the encountered negative association remains unknown. The observed opposite relationships between coloration and performance traits suggests the existence of costs (e.g. darker males may have higher predation because of lower sprint speeds) and/or alternative performance strategies, which is congruent with disruptive selection on sprint speed in juvenile common lizards. Our findings suggest that melanin-based coloration could indicate performance capacity, a hypothesis that deserves further attention considering that, as shown here, more intense coloration may not necessarily reflect a better overall performance.
\end{abstract}

ADDITIONAL KEYWORDS: animal communication - Lacerta [Zootoca] vivipara - locomotor performance maximal bite force - maximal sprint speed - reptile - sexual selection - signal honesty.

\section{INTRODUCTION}

Melanin is the most abundant and widely distributed pigment in the animal kingdom (McGraw, 2006). Melanin deposited in the integument and internal organs protect animals against detrimental abiotic and biotic factors (e.g. ultraviolet radiation; Jablonski \& Chaplin, 2000, abrasion; Bonser, 1995, parasites; Goldstein et al., 2004, see also Dubey \& Roulin, 2014) and influence the outcome of interspecific interactions (Møller, 1987; Tarof, Dunn \& Whittingham, 2005). In

*Corresponding author. E-mail: luis.sanjosegarcia@unil.ch this latter sense, melanin-based coloration plays an important signalling role in many animal taxa, particularly in the context of sexual selection (Owens \& Hartley, 1998; Bókony et al., 2003). Melanin-based coloration have been shown to correlate with different aspects of an individual phenotype that relate to fitness (Roulin, 2016) or with alternative life-history strategies (Roulin et al., 2007; Emaresi et al., 2014). The expression of melanin-based coloration has been shown to be related to differences in hormonal titre (West \& Packer, 2002; San-Jose \& Fitze, 2013), health condition (Galván \& Alonso-Alvarez, 2009; Vroonen, Vervust \& Van Damme, 2013), morphology (Roulin, 
2006), behaviour (van den Brink et al., 2012) and social status (Santos, Scheck \& Nakagawa, 2011) among others (for review, see Ducrest, Keller \& Roulin (2008) and Roulin \& Ducrest (2011)).

Surprisingly, whether melanin-based traits could also signal an individual's performance capacity has rarely been investigated (Plasman et al., 2015). Wholeorganism performance capacity, that is the ability of an animal to conduct an ecologically relevant task (e.g. bite force, flight or swimming speed, endurance capacity; Irschick \& Meyers, 2008), generally results from (and, thereby, summarizes) distinct aspects of an individual's phenotype, given that performing certain tasks can involve the joint expression or co-ordination of morphological, physiological and behavioural traits (Huyghe et al., 2009a, b; Moore \& Hopkins, 2009; Herrel et al., 2013, reviewed in Lailvaux \& Husak, 2014). Traits reflecting performance capacity could evolve in different contexts (Lailvaux \& Irschick, 2006, see also Oufiero \& Garland, 2007, for a discussion on the costs that ornamental traits impose on performance). A better performance commonly entails benefits in contexts of natural selection (e.g. a higher sprint speed allows to escape predators, reviewed in Irschick \& Meyers, 2008) and traits reflecting performance capacity can therefore evolve as signals of the indirect genetic benefits of mating with high-performing individuals (Byers, Hebets \& Podos, 2010). Performance traits can be also directly involved in intra-sexual competition (e.g. bite force; Lappin \& Husak, 2005, spring speed; Husak et al., 2006; Husak \& Fox, 2008; or endurance: Perry et al., 2004), mate choice (e.g. a higher endurance allows for more vigorous courtship displays; Perry et al., 2004) and have direct effects on reproductive success (e.g. through food provisioning to offspring; Snowberg \& Benkman, 2009). Therefore, traits reflecting an individual's performance capacity may be also used in intra-sexual competition to assess a rival's fighting ability and minimize the costs resulting from escalated fights, or during mate choice to assess the potential direct or indirect benefits of mating (Berglund, Bisazza \& Pilastro, 1996; Byers et al., 2010). However, how performance traits relate to fitness is currently under scrutiny, given that nondirectional patterns of selection on performance as well as indirect selection on related traits could play a more relevant role than previously acknowledged (Ghalambor, Walker \& Reznick, 2003; Lailvaux \& Husak, 2014; Cespedes \& Lailvaux, 2015; McCullough $\&$ Simmons, 2016). For instance, endurance in the common lizard, Zootoca vivipara, has multiple links with fitness, being positively associated with growth rate but negatively with predation risk potentially due to a positive association between endurance and activity (Clobert et al., 2000). Thus, under this scenario, whether and how colour traits relate to performance cannot be easily predicted, highlighting that more empirical studies are still needed.

In this study, we investigated whether melanin-based coloration predicts individual performance using male common lizards, $Z$. vivipara as a model species. More specifically, we tested if the ventral melanin-based coloration of male common lizards predicts bite force and sprint speed, both being important performance traits in lizards (Irschick \& Meyers, 2008). Additionally, we used a path analysis to investigate whether the association between coloration and performance results from intermediate associations between coloration and the morphological predictors of performance (see for instance Wilson et al., 2010 for a similar approach).

\section{MATERIAL AND METHODS}

\section{SPECIES DESCRIPTION, STUDY SITES AND SAMPLING}

The common lizard is a small lacertid that inhabits humid habitats (peatbogs and moist heathlands) of Europe and Asia (Sindaco \& Jeremcenko, 2008). Adult male common lizards exhibit a conspicuous ventral coloration that consists of melanin-based black spots (Fig. 1A) and a carotenoid-based coloration that varies into six discrete colour morphs (for further details on male colour morphs, see San-Jose et al., 2014). A previous study indicates that ventral coloration is assessed by conspecifics, given that manipulations of ventral pigmentation altered male mating behaviour (Bauwens et al., 1987). Martin et al. (2013) described that ventral coloration is visible to conspecifics when lizards push up on their fore legs exposing their throat and upper bellies. Throat coloration and belly coloration are strongly correlated (Vroonen et al., 2013). Additionally, ventral coloration spreads over the lateral parts of the lizards' body, and it is thus visible to conspecifics even if no push-ups are conducted (L. M. San-Jose, pers. observ.).

The ventral melanin-based coloration shows a marked sexual dimorphism. Females exhibit none or very few and smaller spots, whereas males present more and larger spots (Vroonen, Vervust \& Van Damme, 2013). In males, spot blackness decreases in response to experimentally increased levels of corticosterone (San-Jose \& Fitze, 2013) and the total area covered by the spots is positively correlated with the immune response induced by the inoculation of phytohemagglutinin (Vroonen et al., 2013). This suggests that black spots have the potential to indicate aspects influencing fitness in this species. In $Z$. vivipara males, the degree of melanization is positively correlated with body size (Vroonen et al., 2013) and the size of the head (measured as the first PC axis on the variation in head length, width, and height and the length of the lower jaw; for further details, see Huyghe et al., 2013) is strongly related with bite force (Huyghe et al., 2013). 

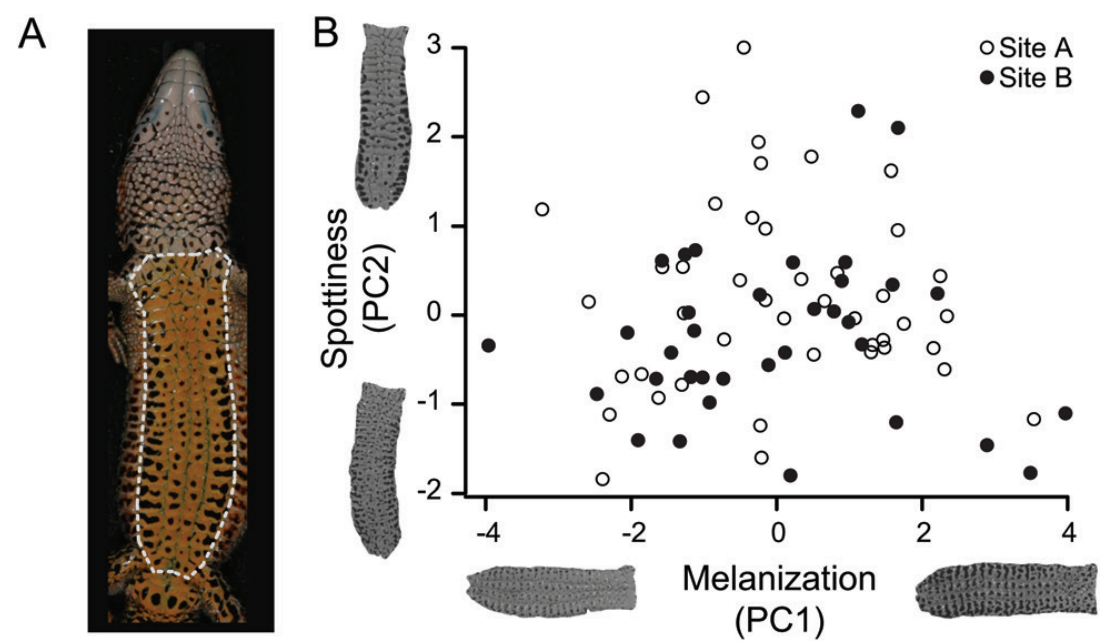

Figure 1. Ventral melanin-based coloration of male common lizards, Zootoca vivipara. (A) Encircled by the grey dotted line is the ventral region selected for the colour measurements, which consists of the four inner longitudinal scale rows from the collar to the anal plate (both not included). (B) Variation in the degree of melanization (PC1) and spot size (PC2) of the melanin-based coloration of male common lizards. Each dot represents one male. Ventral pictures of male lizards shown on each axis correspond to the extreme observations.

During the breeding season of 2010 (end of April and beginning of May), we captured 78 adult males at two different sites of the western Spanish Pyrenees (site A: $n=43$, Puerto de Ibañeta: $43.02^{\circ} \mathrm{N}, 1.32^{\circ} \mathrm{W}, 1062 \mathrm{~m}$ a.s.l.; site B: $n=35$, Puerto de Somport: $43.80^{\circ} \mathrm{N},-0.53^{\circ} \mathrm{W}$, $1640 \mathrm{~m}$ a.s.l.). In each site, we started capturing males the first day females were observed out of hibernation. Thus, males from both localities are expected to be at rather equal stages of reproduction. Lizards were immediately moved to the laboratory at the Instituto Pirenaico de Ecología (Jaca, Huesca, Spain) where colour traits, morphology and performance were measured. Using digital callipers (Mitutoyo), lizard body size [snout-to-vent length (SVL)], head dimension (head length, height and width) and limb dimension (fore- and hind-limb length) were measured to the nearest $0.01 \mathrm{~mm}$. Once the measurements were taken, all the lizards were released at their capture sites.

\section{VENTRAL MELANIN-BASED COLORATION MEASUREMENTS}

Standardized photographs of the ventral view of each lizard were taken as described by Fitze \& Richner (2002) and San-Jose \& Fitze (2013). Using Adobe Photoshop CS4 (Adobe Systems Inc., San Jose, CA, USA), photographs were transformed to a grey scale. A fixed area comprising the scales of the belly and breast was selected (Fig. 1A), and the following parameters were measured: average spot blackness (\%), proportion of black coloration (\%), total number of spots and average spot size (pixels). To measure average spot blackness, a total of 15 spots located on different scales of the posterior, middle and anterior thirds of the ventral region were selected (five spots on each third). Two $5 \times 5$ pixel areas were selected on each spot; one on the core of the spot and another one on the edge of the spot. Selected areas did not include the surrounding white-to-orange coloration. The mean brightness (\%) of each measurement was then obtained using the average filter implemented in Photoshop, and the two measurements taken on the same spot were used to calculate the mean brightness of the spot. The mean of the 15 measured spots was finally obtained and blackness was calculated as 100 - mean brightness, where $100 \%$ reflects completely black and $0 \%$ completely white (see also San-Jose \& Fitze, 2013). The proportion of the belly being black was calculated as the total black surface divided by the total area of the selected ventral region (the initially selected surface, Fig. 1A). The surface of the black spots (i.e. the number of black pixels) was determined using the 'Colour range' tool implemented in Photoshop and using as colour reference the previously calculated mean brightness and a tolerance of $30 \%$. The number of spots was counted on the entire selected ventral region, and the average spot size was calculated by dividing the total black surface ( $N$ pixels) by the number of spots. These colour measurements were all highly repeatable (mean $r=0.95 \pm 0.05 \mathrm{SD}$, all $r>0.90$, $F_{11,12}>18.64, P<0.0001$; Lessells \& Boag, 1987). The coloration of the posterior, middle and anterior thirds of the ventral region were significantly correlated (all $r>0.48$, $N=78$, all $P<0.001$.

\section{PERFORMANCE MEASUREMENTS}

Performance traits (maximal bite force and sprint speed) were measured following a protocol previously 
described for the common lizard (Huyghe et al., 2013). Briefly, before each performance assay, lizards were kept in an incubator at $32{ }^{\circ} \mathrm{C}$, which corresponds to the body temperature that males prefer during the breeding season (van Damme, Bauwens \& Verheyen, 1986). Bite force was measured by making lizards bite five times onto two metal plates connected to a force transducer (Herrel et al., 1999). The strongest bite force (maximal bite force, $\mathrm{N}$ ) measure was used in the statistical analyses. Sprint speed $\left(\mathrm{cm} \mathrm{s}^{-1}\right)$ was measured by chasing the lizards three times down a 2-m-long racetrack (with a minimum of $1 \mathrm{~h}$ between trials) and by filming with a digital video camera at 25 frames $\mathrm{s}^{-1}$. From these recordings, frame-by-frame $x$ and $y$ coordinates indicating lizards' positions in the racetrack were obtained with DIDGE, version 2.3 (http://biology. creighton.edu/faculty/cullum/Didge/), and the highest velocity measured over any 25 -cm distance was retained for further analyses.

\section{STATISTICS}

We first used a principal component analysis to summarize the different colour variables into orthogonal axis. We then tested if the two retained principal components (the PCs summarizing the degree of melanization and spot size, see Results) predicts performance traits using general linear models with a restricted maximum likelihood approach (function gls, package nlme, R v3.0.1, R Foundation for Statistical Computing, Vienna, Austria). Performance traits - bite force and sprint speed - were considered as dependent variables in separate analyses. The degree of melanization, spot size, site and the interactions between site and the degree of melanization, and site and spot size were considered as predictor variables in both models. The models also included male colour morph, since colour morph has been previously shown to influence male performance and endurance (Sinervo et al., 2007). Colour morph was modelled using two colour scores $(O$ score and $W$ score) as described in Sinervo et al. (2007). Briefly, the $O$ and $W$ score for the different morphs were as follows: orange males: $O=2, W=0$, white males: $O=0, W=2$, yellow males: $O=0, W=0$, orangewhite males: $O=1, W=1$, orange-yellow males: $O=1$, $W=0$, white-yellow males: $O=0, W=1$. However, male colour morph was not statistically significant in any of the analyses (all $P>0.26$ ) and for brevity these results were not presented. All models were simplified using backward elimination of the non-significant interactions $(P>0.1)$ between site and melanin-based traits. In line with other studies (e.g. Murtaugh, 2009), this approach yielded qualitatively similar results as likelihood ratio tests and that model comparisons based on Akaike information criterion (AIC) values (not shown).
The effect sizes (partial correlation coefficients, $r$ ) and their $95 \%$ intervals of confidence were calculated for the significant terms in the models following the formulas described in Nakagawa and Cuthill (2007). The statistical power to detect small, moderate and large effect sizes $(r=0.1,0.3,0.5)$ with our sample size of 78 individuals and a $\alpha=0.05$ (two-sided) was $0.14,0.77$ and 0.99 , respectively.

We used structural equation modelling (path analysis) to test whether the association between coloration and performance traits was indirectly mediated through associations between coloration and the morphological traits that could determine performance. We tested 16 candidate models, which together considered all combinations of direct effects of the degree of melanization and SVL on bite force and sprint speed (Fig. 2A, see also Table 1). Because general linear models showed no significant association between spot size and performance (see Results), only the degree of melanization was considered in these models, allowing the simplification of the set of candidate models. Within models, two latent variables were built in order to simplify the analysis. Head dimension and limb dimension, respectively, summarized head measurements (head length, width and height) and limb measurements (fore- and hind-limb length). Models were ranked according to their AIC values, and the set of 'best' models was determined using a cut-off of $\triangle$ AIC $<2$ (Burnham, Anderson \& Huyvaert, 2011). Models were ran using the function sem implemented in the $\mathrm{R}$ package lavaan (Rosseel, 2012).

\section{RESULTS}

The principal component analysis yielded a first PC (hereafter referred to as 'degree of melanization') explaining most of the variance $(66.725 \%$; eigenvalue $=2.67$ ). The proportion of black coloration, average spot size and blackness showed similar moderate positive associations with the first PC (eigenvectors $=0.60,0.57,0.55$, respectively). The number of spots also loaded positively but to a minor extent (eigenvector $=0.103$ ). The second PC explained $25.93 \%$ (eigenvalue $=1.04$ ) of the variance and mainly reflected spot size (hereafter referred to as 'spot size') given that average spot size loaded the highest (eigenvector $=0.96$ ), in relation to the other variables (all eigenvectors $<0.25$ ). The coloration measured at each body part was significantly correlated with these two PC axes (all $r>0.53, N=78$, all $P<0.001$ ). The other two derived PCs explained a relatively small amount of the total variance $(7.35 \%$, eigenvalues $<0.3)$ and were not retained for the subsequent analyses.

Male bite force was positively related with the degree of melanization $\left[F_{1,69}=94.74, P<0.0001\right.$, effect 

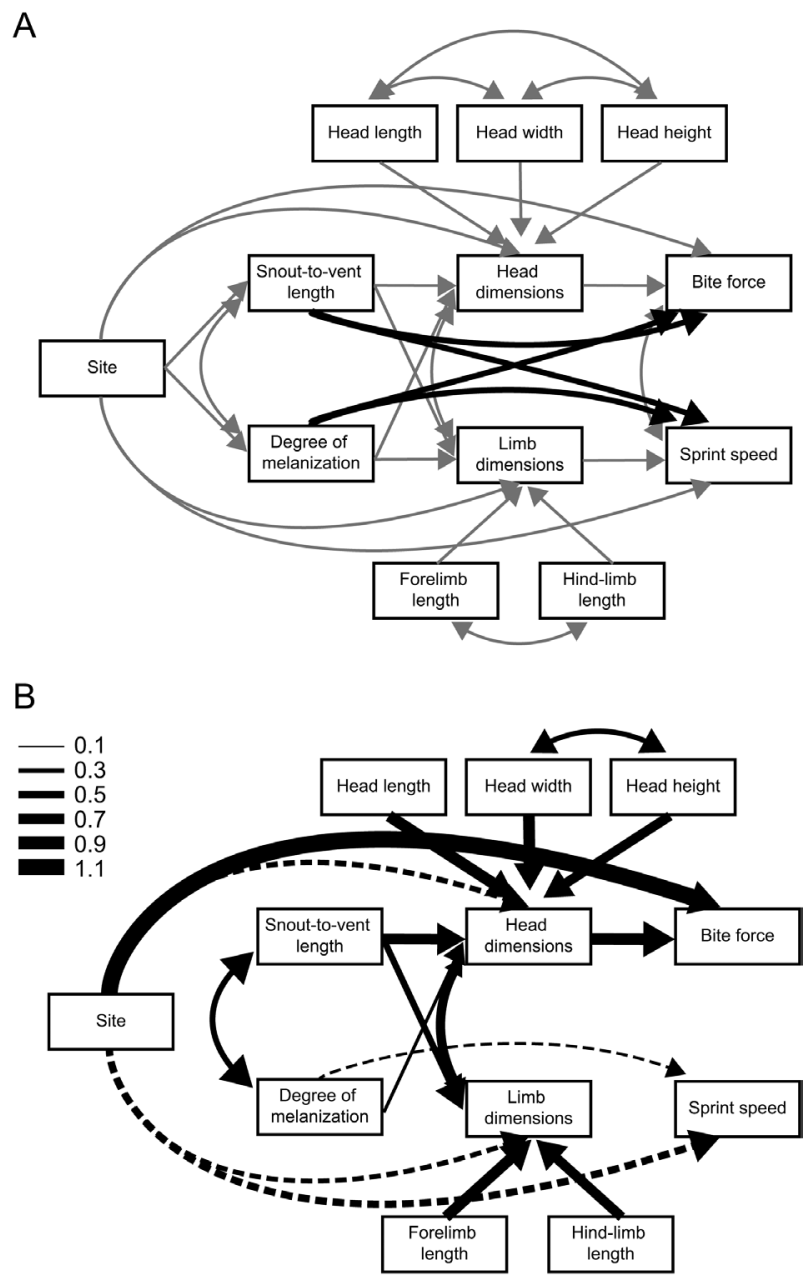

Figure 2. Path analysis on the association between the degree of melanization, morphology and performance. (A) Depicted is the full path model. Grey lines denote the links that were included in all models. The set of candidate models included this full model, the null model (no direct effect of melanization or SVL on performance) and the 14 models that considered all the potential combination of direct effects of the degree of melanization and SVL on performance traits (black lines, see also Table 1). Bidirectional arrows denote covariation between traits. (B) The 'best' path model describing the association between the degree of melanization, morphology and performance (see also Table 1). Arrows denote significant associations between the elements in the path. Non-significant associations are not shown (see Table 2). Arrow thickness is proportional to the effect size of the association and continuous, and dashed lines denote positive and negative associations, respectively. The sign of the effects of 'Site' are plotted considering site B as reference (i.e. continuous lines linking site with other variable indicate larger values of that variable in site B than in site A)

size $r=0.76,95 \%$ confidence interval $(\mathrm{CI})=0.64-0.84$; Fig. 3A] whereas no significant relationship was found between male bite force and spot size $\left(F_{1,69}=2.95\right.$,
$P=0.09)$. Sites significantly differed in male bite force $\left(F_{1,69}=109.39, P<0.0001, r=0.78,95 \%\right.$ CI $=0.71-$ 0.83 ) with males in site B biting stronger than males in site $\mathrm{A}$ [estimated difference in means $( \pm \mathrm{SE})$ of sites $\mathrm{A}$ and $\mathrm{B}=2.47 \pm 0.20 \mathrm{~N}$ ). The interactions between site and the degree of melanization and between site and spot size were not statistically significant (all $P$ $>0.41$ ). Sprint speed was negatively related with the degree of melanization $\left(F_{1.69}=4.83, P=0.031, r=0.25\right.$, $95 \% \mathrm{CI}=0.03-0.45$; Fig. $3 \mathrm{~B}$ ) and no significant relationship was found between sprint speed and spot size $\left(F_{169}=0.27, P=0.61\right)$. Sprint speed was different between the two study sites $\left(F_{169}=29.35, P<0.0001\right.$, $r=0.54,95 \% \mathrm{CI}=0.38-0.66)$. Males in site A were found to run faster than males in site $\mathrm{B}$ [estimated difference in means $( \pm \mathrm{SE})$ of site $\mathrm{A}$ and $\mathrm{B}=-17.03 \pm 3.17 \mathrm{~cm} \mathrm{~s}^{-1}$. The interactions between site and the degree of melanization and between site and spot size were not significant (all $P>0.39$ ).

Among the set of candidate path models describing the relationships between the degree of melanization, morphological traits and performance traits, two models were ranked as 'best' owing to their $\triangle$ AIC below 2 (Table 1). None of these two models support a direct association between the degree of melanization and bite force. The models showed that the encountered positive association between the degree of melanization and bite force (Fig. 3A) was indirectly mediated through the positive associations of these two variables with the latent variable head dimension and through the covariation between the degree of melanization and SVL $(z=4.14, P<0.001)$, which was also positively associated with head dimension (Table 2, Fig. 2B). Head dimension was positively associated with head length $(z=18.31, P<0.001)$, head width $(z=17.49$, $P<0.001)$ and head height $(z=9.44, P<0.001)$. Thus, the positive association between the degree of melanization and head dimension and between SVL and head dimension indicated that more melanized individuals and larger individuals exhibited larger heads. Finally, individuals with larger heads had a stronger bite force. A direct link between SVL and bite force was also included in the 'best' model (Table 1), but the model showed no significant association between these two variables (Table 2). As observed in the linear models, sites were found to differ in bite force and the path analysis showed that sites also differ in head dimension (Table 2, Fig. 2B). Curiously, individuals in site $\mathrm{B}$ bit stronger than individuals in site A but had smaller heads.

The two models ranked as 'best' supported a direct, negative association between sprint speed and the degree of melanization (Table 1, Fig. 2B). This direct association was also included in six out of the eight models with a $\triangle$ AIC below 4 (accumulated weight of 0.63). Limb dimension, a latent variable positively 
Table 1. Comparison of path models describing the association between the degree of melanization, morphology and performance

\begin{tabular}{|c|c|c|c|c|c|c|c|c|}
\hline \multirow[t]{2}{*}{ Model rank } & \multicolumn{2}{|c|}{$\begin{array}{l}\text { Direct effect of } \\
\text { melanization on }\end{array}$} & \multicolumn{2}{|c|}{ Direct effect of SVL on } & \multirow[t]{2}{*}{$\mathrm{AIC}$} & \multirow[t]{2}{*}{$\Delta \mathrm{AIC}$} & \multirow[t]{2}{*}{ ER } & \multirow[t]{2}{*}{$W$} \\
\hline & Bite force & Sprint speed & Bite force & Sprint speed & & & & \\
\hline 1 & No & Yes & Yes & No & 1735.57 & 0 & 1 & 0.17 \\
\hline 2 & No & Yes & No & No & 1735.85 & 0.28 & 1.15 & 0.15 \\
\hline 3 & No & Yes & Yes & Yes & 1737.04 & 1.47 & 2.08 & 0.08 \\
\hline 4 & Yes & Yes & No & No & 1737.12 & 1.55 & 2.17 & 0.08 \\
\hline 5 & No & No & Yes & No & 1737.16 & 1.59 & 2.21 & 0.08 \\
\hline 6 & No & Yes & No & Yes & 1737.38 & 1.81 & 2.47 & 0.07 \\
\hline 7 & Yes & Yes & Yes & No & 1737.45 & 1.88 & 2.56 & 0.07 \\
\hline 8 & No & No & No & No & 1737.48 & 1.91 & 2.60 & 0.07 \\
\hline 9 & Yes & Yes & No & Yes & 1738.64 & 3.07 & 4.65 & 0.04 \\
\hline 10 & Yes & No & No & No & 1738.79 & 3.22 & 5.00 & 0.03 \\
\hline 11 & Yes & Yes & Yes & Yes & 1738.90 & 3.33 & 5.28 & 0.03 \\
\hline 12 & No & No & Yes & Yes & 1738.93 & 3.36 & 5.36 & 0.03 \\
\hline 13 & Yes & No & Yes & No & 1739.01 & 3.44 & 5.57 & 0.03 \\
\hline 14 & No & No & No & Yes & 1739.31 & 3.74 & 6.49 & 0.03 \\
\hline 15 & Yes & No & No & Yes & 1740.59 & 5.02 & 12.33 & 0.01 \\
\hline 16 & Yes & No & Yes & Yes & 1740.76 & 5.19 & 13.40 & 0.01 \\
\hline
\end{tabular}

The candidate models considered all the potential combinations of direct effects of the degree of melanization and SVL on bite force and sprint speed. Models are ranked according to their AIC value, with the null model (no direct effects of melanization and SVL on performance) ranked in eighth position. Evidence ratio (ER) and model weight $(w)$ are also shown. These two parameters account for the probability of a model being the best among the candidate models (weight) and the probability of the best model being better than each of the other candidate models (evidence ratio).

associated with fore- and hind-limb length $(z=9.41$, $P<0.001 ; z=8.04, P<0.001$, respectively), was not significantly associated with sprint speed or with the degree of melanization (Table 2). Limb dimension was positively associated with SVL (larger individuals had larger limbs) and positively co-varied with head dimension ( $z=3.21, P<0.001$, Fig. 2B). The direct effect of SVL on sprint speed was not supported by the 'best' models, and it occurred in only two out of the eight models with a $\triangle \mathrm{AIC}$ below 4 (Table 1 ). As observed in the linear models, sites were found to differ in sprint speed, with individuals in site B running slower than individuals in site $\mathrm{A}$ and the path analysis also showed that individuals from site B had shorter limbs (Table 2, Fig. 2B). Covariation between sprint speed and bite force was not significant $(z=0.11, P=0.91)$.

\section{DISCUSSION}

Our study suggests that the ventral melanin-based coloration of male common lizards, $Z$. vivipara, is related to performance traits that are known to have important effects on a lizard's fitness such as bite force and sprint speed (Irschick \& Meyers, 2008). We found a positive association of large effect size between the degree of melanization and bite force, indicating that males with more melanized ventral parts performed stronger bites. The path analysis supported that the positive association between the degree of melanization and bite force was mediated by the also positive association between the degree of melanization and head dimension and by the association between the degree of melanization and SVL, which was also positively associated with head dimension. Thus, more melanized common lizards seemed to exhibit a stronger bite force because they had larger body sizes and therefore larger heads and because more melanized lizards showed larger heads than less melanized lizards of similar body size (i.e. 'head dimension' was significantly dependent on coloration together with SVL, Table 2).

We also found a negative association between the degree of melanization and sprint speed, indicating that more melanized males ran more slowly than less melanized males. This association was of smallto-moderate effect size $(r=0.25)$ but in the range of effect sizes reported for associations between colour traits with other phenotypic traits (Griffith, Parker \& Olson, 2006; Nakagawa et al., 2007; Santos et al., 2011). It should be considered cautiously given that our study had moderate statistical power $(0.60)$ to detect an effect of such magnitude (Nakagawa \& Cuthill, 2007). The path analysis supported a direct association between the degree of melanization and sprint speed. However, limb dimension or body size, 

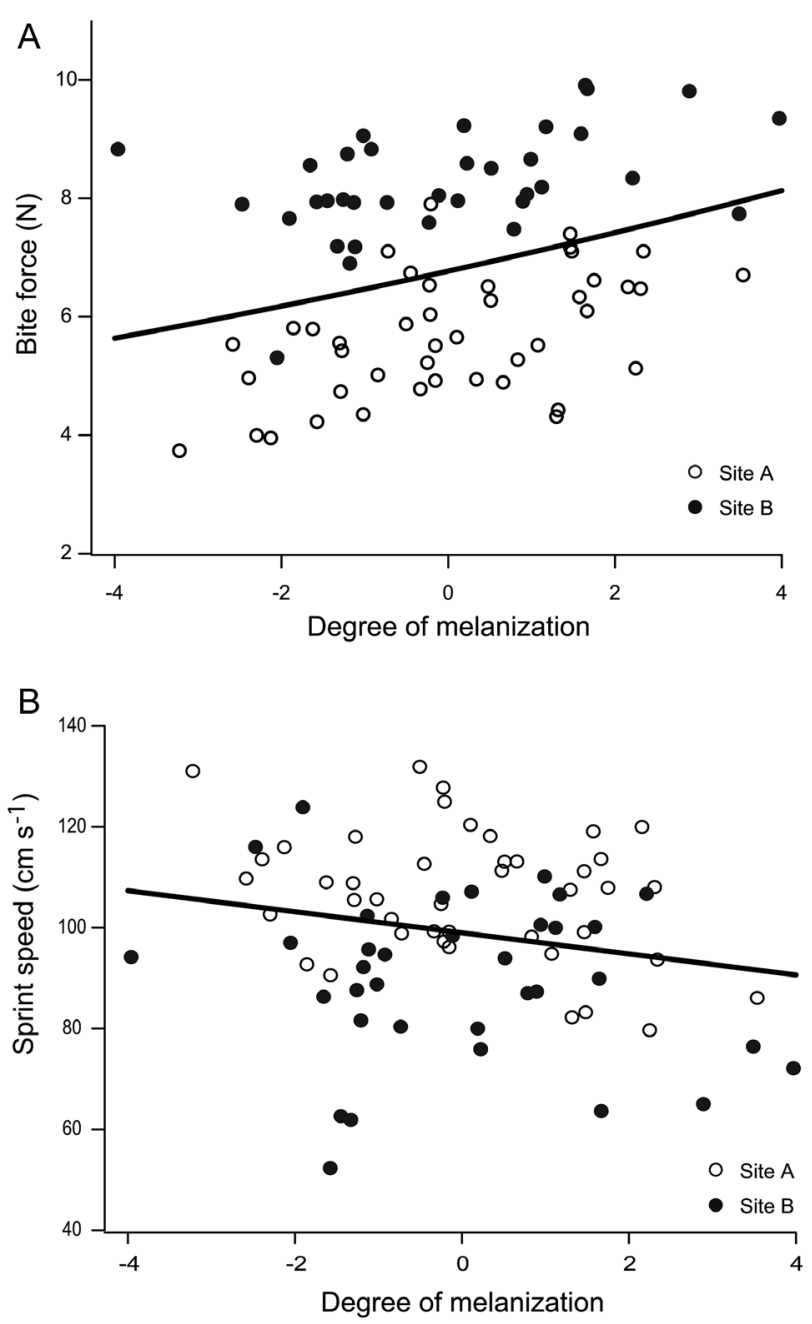

Figure 3. Relationship between performance and the degree of melanization of the ventral coloration of male common lizards, Zootoca vivipara. Shown are the relationships between the degree of melanization and bite force (A) or sprint speed (B). Shown are the observed values and the predicted regression lines.

which are good predictors of sprint speed in other lizard species (Goodman, Miles \& Schwarzkopf, 2008; Brandt et al., 2016), were not associated here with sprint speed, indicating that additional morphological predictors (muscle mass measurements, for instance: Vanhooydonck et al., 2006) would be needed to assess whether and how melanization associates to sprint speed through other morphological traits.

The observed association between melanin-based coloration and performance is partly in line with recent findings in the Dickerson's collared lizard, Crotaphytus dickersonae (Plasman et al., 2015), and support that melanin-based coloration, the most widespread type of coloration in animals (McGraw, 2006), could potentially signal aspects of individual performance. However, the results encountered here raise the possibility that a more melanized coloration is not positively related with all measured performance traits, given that more melanized lizards were found to bite more strongly but also to run more slowly than less melanized lizards. Because ornamental expression is commonly thought to be associated with phenotypic aspects that positively relate to fitness (Zahavi, 1975; Getty, 1998; Hill, 2011) and performance traits are generally thought to be under positive directional selection (Irschick \& Meyers, 2008), colour traits in general are commonly expected to indicate a better performance. This is generally supported by previous studies on other types of coloration (Huyghe et al., 2005; Meyers et al., 2006; Lai, Kekäläinen \& Kortet, 2013) and also in relation to melanin-based coloration, as in the case of the Dickerson's collared lizard, where both sprint speed and the size of the adductor mandibulae complex (a proxy of bite force) were positively related with the size of the black area of the collar (Plasman et al., 2015). However, the fact that, as suggested here, melanin-based coloration relates to different performance traits in opposite directions suggests that, as recently recognized (Lailvaux \& Husak, 2014), the joint expression and evolution of colour and performance traits could be of major complexity.

The opposite associations between coloration and bite force and between coloration and sprint speed could be interpreted as a performance trade-off that only becomes evident when coloration is also taken into account. In other words, high bite force values associate with low sprint speed values in lizards with more melanized bellies and, contrarily, low bite force values associate with high sprint speed values in lizards with less melanized bellies. Performance tradeoffs can result as a consequence of developmental and genetic constraints (e.g. shared resources or morphologies, and through epistatic or pleiotropic allelic effects; Cheverud, 1996), as well as through correlational selection even if performance traits are independently expressed and inherited (Sinervo \& Svensson, 2002). Trade-offs between bite force and sprint speed have been previously observed in lizards (López \& Martín, 2002; Cameron, Wynn \& Wilson, 2013) but also positive associations between both traits (Huyghe et al., 2005; Plasman et al., 2015), indicating that a tradeoff between sprint speed and bite force is not a general consequence of lizards' body plan but specific to certain evolutionary contexts. In our study, the path analysis found no statistical support for a negative relationship between bite force and sprint speed (no significant association was observed, Fig. 2B), indicating that a direct, general trade-off between the studied performance traits cannot explain why more 
Table 2. Summary of the results from the path analysis

\begin{tabular}{|c|c|c|c|c|}
\hline Model terms & Standardized estimate & Standard error & $Z$ & $P$ \\
\hline \multicolumn{5}{|c|}{ Direct effects on bite force } \\
\hline SVL & -0.26 & 0.21 & -1.27 & 0.205 \\
\hline Head dimension & 0.80 & 0.24 & 3.31 & $<0.001$ \\
\hline Site & 1.14 & 0.11 & 9.95 & $<0.001$ \\
\hline \multicolumn{5}{|c|}{ Direct effects on sprint speed } \\
\hline Melanization & -0.21 & 0.11 & -1.95 & 0.052 \\
\hline Limb dimension & 0.03 & 0.14 & 0.21 & 0.836 \\
\hline Site & -0.49 & 0.09 & -5.23 & $<0.001$ \\
\hline \multicolumn{5}{|c|}{ Direct effects on head dimension } \\
\hline Melanization & 0.21 & 0.07 & 3.15 & 0.002 \\
\hline SVL & 0.72 & 0.07 & 10.70 & $<0.001$ \\
\hline Site & -0.39 & 0.07 & -5.61 & $<0.001$ \\
\hline \multicolumn{5}{|c|}{ Direct effects on limb dimension } \\
\hline Melanization & 0.19 & 0.12 & 1.59 & 0.112 \\
\hline SVL & 0.44 & 0.12 & 3.77 & $<0.001$ \\
\hline Site & -0.34 & 0.11 & -3.16 & 0.002 \\
\hline \multicolumn{5}{|l|}{ Direct effects on SVL } \\
\hline Site & -0.10 & 0.11 & -0.87 & 0.383 \\
\hline \multicolumn{5}{|c|}{ Direct effects on melanization } \\
\hline Site & -0.02 & 0.11 & -0.19 & 0.847 \\
\hline
\end{tabular}

Shown are the statistics from the path model ranked as best (Model 1 in Table 1). The second-best model yielded qualitatively similar results with the exception that it did not considered the direct effect of SVL on bite force.

melanized individuals bit more strongly but ran more slowly in our study.

From a proximate or mechanistic point of view, different factors could explain why melanin-based coloration could be differently related to bite force and sprint speed. On the one hand, the fact that the degree of melanization was strongly associated with body size could indicate that melanization increases with age in the common lizard, given that body size and age are strongly correlated in lizards (Olsson \& Shine, 1996, although see Halliday \& Verrell, 1988). Thus, the effect observed here could reflect an agerelated trade-off (e.g. Heidinger, Nisbet \& Ketterson, 2006) between performance traits. On the other hand, dark and light coloured individuals often differ in hormonal levels, which can also induce differences directly in performance or indirectly by affecting the development of morphological traits. For instance, testosterone positively influences the expression of melanin-based traits in lizards (Cox et al., 2008, although see Calisi \& Hews, 2007) and other vertebrates (Gonzalez et al., 2001; West \& Packer, 2002; Spinney, Bentley \& Hau, 2006) and is often positively related with bite force, at least in related lizard species (Cox et al., 2009; Huyghe et al., 2009a, b; Plasman et al., 2015). Thus, differences in testosterone levels could explain why darker common lizard males bite stronger. However, it will be necessary to consider the role of testosterone in determining sprint speed in the common lizard given that, to date, negative but also positive or not significant associations between sprint speed and testosterone have been reported in lizards (Klukowski, Jenkinson \& Nelson, 1998; Husak et al., 2006; Cox et al., 2009; Huyghe et al., 2010).

The fact that different performance traits could be reversely related with melanin-based coloration suggests that increasing the degree of melanization could entail costs to individuals (i.e. as a consequence of reduced sprint speed) and/or that the degree of melanization may reflect different life-history (e.g. Ortega et al., 2015) or behavioural strategies (for instance, to escape predators: Roches et al., 2014). We can expect the degree of melanization to be an evolutionary stable signal in both scenarios (Maynard-Smith \& Harper, 2003). However, understanding whether ventral melanin-based coloration plays any signalling role in the common lizard requires deeper empirical knowledge on the link between the degree of melanization, performance traits and fitness. This is necessary to discard the role of neutral mechanisms in shaping associations between melanization and performance traits. Neutral forces, such as genetic constraints, are particularly likely in this context because the synthesis of melanin in vertebrates is under the control of the highly pleiotropic melanocortin system, which also regulates multiple physiological and behavioural aspects and accounts for associations between melanin-based 
traits and other phenotypic aspects (Ducrest et al., 2008; Emaresi et al., 2013; San-Jose et al., 2017).

Previous studies allow to think that the degree of melanization in male common lizards could be under selection, given that it associates with traits that have been previously observed to affect fitness in this species: body size, head size and bite force. Female common lizards preferentially mate with males of larger body size (Fitze et al., 2008), and males with larger heads grasp females faster during copulations and are dominant over males with smaller heads (even for the same body size; Gvozdík \& Van Damme, 2003). This suggests that the degree of melanization could be under positive directional selection and it could signal morphological difference and/or dominance, which could be used by females and/or other males to assess mates or competitors. A more recent study found that, for males of similar body size, males with a weaker bite force copulated before males with stronger bites (Huyghe et al., 2013), suggesting that female mate choice may limit the intensity of positive selection on bite force and indirectly on the degree of melanization.

Previous studies found no link between sprint speed and a male's copulation probability (Husak et al., 2006; Husak \& Fox, 2008; Huyghe et al., 2013) and the fact that in the common lizard males and females run equally fast suggests that sexual selection plays a minor role on the evolution of sprint speed (Huyghe et al., 2013). Sprint speed might be under natural selection given that, at least in juvenile common lizards, survival depends on a complex interaction between sprint speed and exploratory behaviour (Le Galliard et al., 2013). Namely, lizards that run faster survive better when displaying less exploratory behaviours and lizards that run more slowly survive better when displaying more exploratory behaviours (Le Galliard et al., 2013). Whether common lizards with a higher degree of ventral melanization also exhibit a higher exploratory behaviour is unknown. The existence of such link is possible given that it has been repeatedly shown in different vertebrates (Mateos-Gonzalez \& Senar, 2012; Ibáñez et al., 2016) and is expected given that the same regulatory genetic network underlies melanin synthesis and exploratory behaviour (Ducrest et al., 2008; Karlsson et al., 2010). It is nevertheless necessary to empirically confirm the existence of such association in male common lizards as well as the existence in adult lizards of a similar complex relationship between survival, sprint speed and exploratory behaviour than the one observed in juveniles. Confirming this could indicate that the slower speed of more melanized individuals may not necessarily entail a direct cost (Vanhooydonck et al., 2007; Huggins et al., 2010; Le Galliard et al., 2013) and that the degree of melanization could be associated with alternative life-history or behavioural strategies rather than with male quality as expected in scenarios of signal evolution such as the handicap model (Zahavi, 1975).

The relationship between performance and colour traits may be labile and exist only in certain populations of the same species. For instance, Nicoletto \& Kodric-Brown (1999) found that swimming performance positively correlates with the number of spots in one but not in the other three studied populations of guppies, Poecilia reticulata. Here, the relationship between melanin-based coloration and performance did not significantly differ between populations (no significant interactions were found), which supports the generality of the relationships encountered. However, we observed substantial divergence in performance between sites and no evidence of a parallel change in melanin-based coloration even though the associations encountered here between performance traits and the degree of melanization would predict such change. Moreover, we also observed that head dimension was significantly smaller in site B than in site A (Fig. 2B). This contrasts again with the lack of differences between sites in the degree of melanization, which was positively associated with head dimension, but also with the fact that males in site B were found to bite more strongly despite the positive and strong association between head dimension and bite force (Fig. 2B). These findings support that, despite the associations observed among coloration, morphology and performance, these traits can evolve independently or be sensitive to environmental factors to different extents. Other factors than those considered in this study could be therefore of substantial importance in explaining variation between populations in these traits, and future studies should uncover them as well as their influence in explaining variation within populations, where any signalling role of melanin-based coloration would be at play.

To summarize, this study showed that melaninbased coloration can be related with different performance traits in common lizards, supporting that melanin-based coloration can signal performance capacity. The sign of the relationships differed between performance traits, suggesting the existence of a trade-off between bite force and sprint speed that becomes evident when differences in coloration are taken into account. Such performance trade-offs may be indicative of costs associated with the expression of melanin-based traits or of the existence of alternative strategies associated with coloration (Calsbeek \& Irschick, 2007). Further studies are nevertheless needed to confirm the negative association observed between melanization and sprint speed and to unravel how melanization and performance relate to fitness in adult males. Such studies must take into account neutral explanations to the associations encountered 
here (e.g. owing to pleiotropic linkage: Lande, 1980) as well as the intra-population role of yet-to-be-discovered factors in driving the here-observed differences between sites in performance. In line with the current theoretical framework and empirical studies (Cespedes \& Lailvaux, 2015; McCullough \& Simmons, 2016), our study depicts a more complex scenario on the interplay between the potential signalling role of animal coloration and performance.

\section{ACKNOWLEDGEMENTS}

We thank Miguel Peñalver-Alcázar for field and laboratory assistance, Carlos Zaragoza for helping in developing the colour measurements and three anonymous reviewers for their helpful comments on earlier versions of the manuscript. The capture and handling of lizards was conducted under the licenses provided by the Gobierno de Navarra and Aragón. The work was supported by the Spanish Ministry of Education and Science (CGL2005-01187 and CGL2008-01522) and the Swiss National Science Foundation (PPOOP3_128375 and PP00P3_152929/1) to PSF. KH is a postdoctoral fellow of FWO-Fl. The data used in this study are available as Supporting Information.

\section{REFERENCES}

Bauwens D, Nuijten K, van Wezel H, Verheyen RF. 1987. Sex recognition by males of the lizard Lacerta vivipara: an introductory study. Amphibia-Reptilia 8: 49-57.

Berglund A, Bisazza A, Pilastro A. 1996. Armaments and ornaments: an evolutionary explanation of traits of dual utility. Biological Journal of the Linnean Society 58: 385-399.

Bókony V, Liker A, Székely T, Kis J. 2003. Melanin-based plumage coloration and flight displays in plovers and allies. Proceedings of the Royal Society of London B: Biological Sciences 270: 2491-2497.

Bonser RHC. 1995. Melanin and the abrasion resistance of feathers. The Condor 97: 590-591.

Brandt R, de Barros FC, Noronha C, Tulli MJ, Kohlsdorf T. 2016. Sexual differences in locomotor performance in Tropidurus catalanensis lizards (Squamata: Tropiduridae) - body shape, size and limb musculature explain variation between males and females. Biological Journal of the Linnean Society 118: 598-609.

van den Brink V, Henry I, Wakamatsu K, Roulin A. 2012. Melanin-based coloration in juvenile kestrels (Falco tinnunculus) covaries with anti-predatory personality traits. Ethology 118: 673-682.

Burnham KP, Anderson DR, Huyvaert KP. 2011. AIC model selection and multimodel inference in behavioral ecology: some background, observations, and comparisons. Behavioral Ecology and Sociobiology 65: 23-35.
Byers J, Hebets E, Podos J. 2010. Female mate choice based upon male motor performance. Animal Behaviour 79: 771-778.

Calisi R, Hews D. 2007. Steroid correlates of multiple color traits in the spiny lizard, Sceloporus pyrocephalus. Journal of Comparative Physiology B: Biochemical, Systemic, and Environmental Physiology 177: 641-654.

Calsbeek R, Irschick DJ. 2007. The quick and the dead: correlational selection on morphology, performance, and habitat use in island lizards. Evolution 61: 2493-2503.

Cameron SF, Wynn ML, Wilson RS. 2013. Sex-specific tradeoffs and compensatory mechanisms: bite force and sprint speed pose conflicting demands on the design of geckos (Hemidactylus frenatus). Journal of Experimental Biology 216: 3781-3789.

Cespedes AM, Lailvaux SP. 2015. An individual-based simulation approach to the evolution of locomotor performance. Integrative and Comparative Biology 55: 1176-1187.

Cheverud JM. 1996. Developmental integration and the evolution of pleiotropy. Integrative and Comparative Biology 36: $44-50$.

Clobert J, Oppliger A, Sorci G, Ernande B, Swallow JG, Garland T. 2000. Trade-offs in phenotypic traits: endurance at birth, growth, survival, predation and susceptibility to parasitism in a lizard, Lacerta vivipara. Functional Ecology 14: $675-684$.

Cox RM, Stenquist DS, Henningsen JP, Calsbeek R. 2009. Manipulating testosterone to assess links between behavior, morphology, and performance in the brown anole Anolis sagrei. Physiological and Biochemical Zoology 82: 686-698.

Cox RM, Zilberman V, John-Alder HB, Viktoriya Z. 2008. Testosterone stimulates the expression of a social color signal in Yarrow's spiny lizard, Sceloporus jarrovii. Journal of Experimental Zoology A: Ecological Genetics and Physiology 309A: 505-514.

van Damme R, Bauwens D, Verheyen R. 1986. Selected body temperatures in the lizard Lacerta vivipara: variation within and between populations. Journal of Thermal Biology 11: 219-222.

Dubey S, Roulin A. 2014. Evolutionary and biomedical consequences of internal melanins. Pigment Cell \& Melanoma Research 27: 327-338.

Ducrest AL, Keller L, Roulin A. 2008. Pleiotropy in the melanocortin system, coloration and behavioural syndromes. Trends in Ecology \& Evolution 23: 502-510.

Emaresi G, Bize P, Altwegg R, Henry I, van den Brink V, Gasparini J, Roulin A. 2014. Melanin-specific life-history strategies. The American Naturalist 183: 269-280.

Emaresi G, Ducrest AL, Bize P, Richter H, Simon C, Roulin A. 2013. Pleiotropy in the melanocortin system: expression levels of this system are associated with melanogenesis and pigmentation in the tawny owl (Strix aluco). Molecular Ecology 22: 4915-4930.

Fitze PS, Cote J, Martínez-Rica JP, Clobert J. 2008. Determinants of male fitness: disentangling intra-and inter-sexual selection. Journal of Evolutionary Biology 21: $246-255$. 
Fitze PS, Richner H. 2002. Differential effects of a parasite on ornamental structures based on melanins and carotenoids. Behavioral Ecology 13: 401-407.

Galván I, Alonso-Alvarez C. 2009. The expression of melanin-based plumage is separately modulated by exogenous oxidative stress and a melanocortin. Proceedings of the Royal Society of London B: Biological Sciences 276: 3089-3097.

Getty T. 1998. Handicap signalling: when fecundity and viability do not add up. Animal Behaviour 56: 127-130.

Ghalambor C, Walker J, Reznick DN. 2003. Multi-trait selection, adaptation, and constraints on the evolution of burst swimming performance. Integrative and Comparative Biology 43: 431-438.

Goldstein G, Flory KR, Browne BA, Majid S, Ichida JM, Burtt EH. 2004. Bacterial degradation of black and white feathers. The Auk 121: 656-659.

Gonzalez G, Sorci G, Smith LC, Lope F. 2001. Testosterone and sexual signalling in male house sparrows (Passer domesticus). Behavioral Ecology and Sociobiology 50: 557-562.

Goodman BA, Miles DB, Schwarzkopf L. 2008. Life on the rocks: habitat use drives morphological and performance evolution in lizards. Ecology 89: 3462-3471.

Griffith SC, Parker TH, Olson VA. 2006. Melanin- versus carotenoid-based sexual signals: is the difference really so black and red? Animal Behaviour 71: 749-763.

Gvozdík L, Van Damme R. 2003. Evolutionary maintenance of sexual dimorphism in head size in the lizard Zootoca vivipara: a test of two hypotheses. Journal of Zoology 259: 7-13.

Halliday TR, Verrell, PA. 1988. Body size and age in amphibians and reptiles. Journal of Herpetology 22: 253-265.

Heidinger BJ, Nisbet ICT, Ketterson ED. 2006. Older parents are less responsive to a stressor in a long-lived seabird: a mechanism for increased reproductive performance with age? Proceedings of the Royal Society of London B: Biological Sciences 273: 2227-2231.

Herrel A, Andrade DV, de Carvalho JE, Brito A, Abe A, Navas C. 2013. Aggressive behavior and performance in the tegu lizard Tupinambis merianae. Physiological and Biochemical Zoology 82: 680-685.

Herrel A, Spithoven L, van Damme R, De Vree F. 1999. Sexual dimorphism of head size in Gallotia galloti: testing the niche divergence hypothesis by functional analyses. Functional Ecology 13: 289-297.

Hill GE. 2011. Condition-dependent traits as signals of the functionality of vital cellular processes. Ecology Letters 14: 625-634.

Huggins K, Navara K, Mendonça M, Hill G. 2010. Detrimental effects of carotenoid pigments: the dark side of bright coloration. Naturwissenschaften 97: 637-644.

Husak J, Fox S. 2008. Sexual selection on locomotor performance. Evolutionary Ecology Research 10: 213-228.

Husak JF, Fox SF, Lovern MB, Bussche RA. 2006. Faster lizards sire more offspring: sexual selection on whole-animal performance. Evolution 60: 2122-2130.

Huyghe K, Herrel A, Adriaens D, Tadić Z, Van Damme R. 2009a. It is all in the head: morphological basis for differences in bite force among colour morphs of the Dalmatian wall lizard. Biological Journal of the Linnean Society 96: 13-22.

Huyghe K, Husak JF, Herrel A, Tadić Z, Moore IT, Van Damme R, Vanhooydonck B. 2009b. Relationships between hormones, physiological performance and immunocompetence in a color-polymorphic lizard species, Podarcis melisellensis. Hormones and Behavior 55: 488-494.

Huyghe K, Husak JF, Moore IT, Vanhooydonck B, Van Damme R, Molina-Borja M, Herrel A. 2010. Effects of testosterone on morphology, performance and muscle mass in a lizard. Journal of Experimental Zoology A: Ecological Genetics and Physiology 313: 9-16.

Huyghe K, San-Jose LM, Peñalver Alcazar M, Fitze PS. 2013. An ecomorphological analysis of the determinants of mating success. Biological Journal of the Linnean Society 110: $658-664$.

Huyghe K, Vanhooydonck B, Scheers H, Molina-Borja M, Van Damme R. 2005. Morphology, performance and fighting capacity in male lizards, Gallotia galloti. Functional Ecology 19: 800-807.

Ibáñez A, Pellitteri-Rosa D, Sacchi R, López P, Martín J. 2016. Melanin-based coloration covaries with hiding and exploratory behavior in male Spanish terrapins. Ethology 122: $30-36$

Irschick D, Meyers J. 2008. How does selection operate on whole-organism functional performance capacities? A review and synthesis. Evolutionary Ecology Research 10: 177-196.

Jablonski NG, Chaplin G. 2000. The evolution of human skin coloration. Journal of Human Evolution 39: 57-106.

Karlsson AC, Kerje S, Andersson L, Jensen P. 2010. Genotype at the PMEL17 locus affects social and explorative behaviour in chickens. British Poultry Science 51: 170-177.

Klukowski M, Jenkinson NM, Nelson CE. 1998. Effects of testosterone on locomotor performance and growth in fieldactive northern fence lizards, Sceloporus undulatus hyacinthinus. Physiological Zoology 71: 506-514.

Lai YT, Kekäläinen J, Kortet R. 2013. Male ornamentation in the European minnow (Phoxinus phoxinus) signals swimming performance. Ethology 119: 1077-1085.

Lailvaux SP, Husak JF. 2014. The life-history of wholeorganism performance. The Quarterly Review of Biology 89: 285-318.

Lailvaux SP, Irschick DJ. 2006. A functional perspective on sexual selection: insights and future prospects. Animal Behaviour 72: 263-273.

Lande R. 1980. The genetic covariance between characters maintained by pleiotropic mutations. Genetics 94: 203-215.

Lappin AK, Husak JF. 2005. Weapon performance, not size, determines mating success and potential reproductive output in the collared lizard (Crotaphytus collaris). The American Naturalist 166: 426-436.

Lessells CM, Boag AM. 1987. Unrepeatable repeatabilities: a common mistake. The Auk 104: 116-121.

Le Galliard JF, Paquet M, Cisel M, Montes-Poloni L. 2013. Personality and the pace-of-life syndrome: variation and selection on exploration, metabolism and locomotor performances. Functional Ecology 27: 136-144. 
López P, Martín J. 2002. Locomotor capacity and dominance in male lizards Lacerta monticola: a trade-off between survival and reproductive success? Biological Journal of the Linnean Society 77: 201-209.

Martin M, Meylan S, Gomez D, Le Galliard JF. 2013. Ultraviolet and carotenoid-based coloration in the viviparous lizard Zootoca vivipara (Squamata: Lacertidae) in relation to age, sex, and morphology. Biological Journal of the Linnean Society 110: 128-141.

Mateos-Gonzalez F, Senar JC. 2012. Melanin-based trait predicts individual exploratory behaviour in siskins, Carduelis spinus. Animal Behaviour 83: 229-232.

Maynard-Smith J, Harper DGC. 2003. Animal signals. Oxford: Oxford University Press.

McCullough EL, Simmons LW. 2016. Selection on male physical performance during male-male competition and female choice. Behavioral Ecology 27: 1288-1295.

McGraw KJ. 2006. Mechanics of melanin-based coloration. In: McGraw KJ, Hill GE, eds. Bird coloration. Cambridge: Harvard University Press, 243-294.

Meyers JJ, Irschick DJ, Vanhooydonck B, Herrel A. 2006. Divergent roles for multiple sexual signals in a polygynous lizard. Functional Ecology 20: 709-716.

Møller AP. 1987. Social control of deception among status signalling house sparrows Passer domesticus. Behavioral Ecology and Sociobiology 20: 307-311.

Moore IT, Hopkins WA. 2009. Interactions and trade-offs among physiological determinants of performance and reproductive success. Integrative and Comparative Biology 49: 441-451.

Murtaugh PA. 2009. Performance of several variable-selection methods applied to real ecological data. Ecology Letters 12: 1061-1068.

Nakagawa S, Cuthill IC. 2007. Effect size, confidence interval and statistical significance: a practical guide for biologist. Biological Reviews 82: 591-605.

Nakagawa S, Ockendon N, Gillespie DOS, Hatchwell BJ, Burke T. 2007. Assessing the function of house sparrows' bib size using a flexible meta-analysis method. Behavioral Ecology 18: 831-840.

Nicoletto P, Kodric-Brown A. 1999. The relationship among swimming performance, courtship behavior, and carotenoid pigmentation of guppies in four rivers of Trinidad. Environmental Biology of Fishes 55: 227-235.

Olsson M, Shine R. 1996. Does reproductive success increase with age or with size in species with indeterminate growth? A case study using sand lizards (Lacerta agilis). Oecologia 105: $175-178$.

Ortega J, Pellitteri-Rosa D, López P, Martín J. 2015. Dorsal pattern polymorphism in female Iberian wall lizards: differences in morphology, dorsal coloration, immune response, and reproductive investment. Biological Journal of the Linnean Society 116: 352-363.

Oufiero CE, Garland T. 2007. Evaluating performance costs of sexually selected traits. Functional Ecology 21: 676-689.

Owens IPF, Hartley IR. 1998. Sexual dimorphism in birds: why are there so many different forms of dimorphism?
Proceedings of the Royal Society of London B: Biological Sciences 265: 397-407.

Perry G, LeVering K, Girard I, Garland T. 2004. Locomotor performance and social dominance in male Anolis cristatellus. Animal Behaviour 67: 37-47.

Plasman M, Reynoso VH, Nicolás L, Torres R. 2015. Multiple colour traits signal performance and immune response in the Dickerson's collared lizard Crotaphytus dickersonae. Behavioral Ecology and Sociobiology 69: 765-775.

Roches SD, Torresdal J, Morgan TW, Harmon LJ, Rosenblum EB. 2014. Beyond black and white: divergent behaviour and performance in three rapidly evolving lizard species at White Sands. Biological Journal of the Linnean Society 111: 169-182.

Rosseel Y. 2012. lavaan: an $R$ package for structural equation modeling. Journal of Statistical Software 48: 1-36.

Roulin A. 2006. Linkage disequilibrium between a melaninbased colour polymorphism and tail length in the barn owl. Biological Journal of the Linnean Society 88: 475-488.

Roulin A. 2016. Condition-dependence, pleiotropy and the handicap principle of sexual selection in melanin-based colouration. Biological Reviews 91: 328-348.

Roulin A, Ducrest AL. 2011. Association between melanism, physiology and behaviour: a role for the melanocortin system. European Journal of Pharmacology 660: 226-233.

Roulin A, Gasparini J, Bize P, Ritschard M, Richner H. 2007. Melanin-based colorations signal strategies to cope with poor and rich environments. Behavioral Ecology and Sociobiology 62: 507-519.

San-Jose LM, Ducrest AL, Ducret V, Simon, C, Richter H, Wakamatsu K, Roulin A. 2017. $M C 1 R$ variants affect the expression of melanocortin and melanogenic genes and the association between melanocortin genes and coloration. Molecular Ecology 26: 259-276.

San-Jose LM, Fitze PS. 2013. Corticosterone regulates multiple colour traits in Lacerta [Zootoca] vivipara males. Journal of Evolutionary Biology 26: 2681-2690.

San-Jose LM, Peñalver-Alcázar M, Milá B, GonzalezJimena V, Fitze PS. 2014. Cumulative frequency-dependent selective episodes allow for rapid morph cycles and rock-paper-scissors dynamics in species with overlapping generations. Proceedings of the Royal Society of London B: Biological Sciences 281: 20140976.

Santos ESA, Scheck D, Nakagawa S. 2011. Dominance and plumage traits: meta-analysis and metaregression analysis. Animal Behaviour 82: 3-19.

Sindaco R, Jeremcenko VK. 2008. The reptiles of the Western Paleartic. Latina: Edizioni Belvedere.

Sinervo B, Heulin B, Surget-Groba Y, Clobert J, Miles DB, Corl A, Chaine A, Davis A. 2007. Models of densitydependent genic selection and a new rock-paper-scissors social system. The American Naturalist 170: 663-680.

Sinervo B, Svensson E. 2002. Correlational selection and the evolution of genomic architecture. Heredity 89: 329-338.

Snowberg LK, Benkman CW. 2009. Mate choice based on a key ecological performance trait. Journal of Evolutionary Biology 22: 762-769. 
Spinney LH, Bentley GE, Hau M. 2006. Endocrine correlates of alternative phenotypes in the white-throated sparrow (Zonotrichia albicollis). Hormones and Behavior 50: 762-771.

Tarof SA, Dunn PO, Whittingham LA. 2005. Dual functions of a melanin-based ornament in the common yellowthroat. Proceedings of the Royal Society of London B: Biological Sciences 272: 1121-1127.

Vanhooydonck B, Herrel A, Van Damme R, Irschick DJ. 2006. The quick and the fast: the evolution of acceleration capacity in Anolis lizards. Evolution 60: 2137-2147.

Vanhooydonck B, Van Damme R, Herrel A, Irschick DJ. 2007. A performance based approach to distinguish indices from handicaps in sexual selection studies. Functional Ecology 21: $645-652$.
Vroonen J, Vervust B, Van Damme R. 2013. Melanin-based colouration as a potential indicator of male quality in the lizard Zootoca vivipara (Squamata: Lacertidae). AmphibiaReptilia 34: 539-549.

West PM, Packer C. 2002. Sexual selection, temperature, and the lion's mane. Science 297: 1339-1343.

Wilson RS, Condon CH, David G, Fitzgibbon S, Niehaus AC, Pratt K. 2010. Females prefer athletes, males fear the disadvantaged: different signals used in female choice and male competition have varied consequences. Proceedings of the Royal Society of London B: Biological Sciences 277: 1923-1928.

Zahavi A. 1975. Mate selection: a selection for a handicap. Journal of Theoretical Biology 53: 205-214.

\section{SUPPORTING INFORMATION}

Additional Supporting Information may be found in the online version of this article at the publisher's web-site:

Table S1. Data set of coloration and performance of male common lizards. 